\title{
Chronic Inflammation and Neutrophil Activation as Possible Causes of Joint Diseases in Ballet Dancers
}

\author{
Leandro da Silva Borges, ${ }^{1}$ José Ricardo Bortolon, ${ }^{1}$ Vinicius Coneglian Santos, ${ }^{1,2}$ \\ Nivaldo Ribeiro de Moura, ${ }^{1}$ Alexandre Dermargos, ${ }^{1}$ Maria Fernanda Cury-Boaventura, \\ Renata Gorjão, ${ }^{1}$ Tania Cristina Pithon-Curi, ${ }^{1,2}$ and Elaine Hatanaka ${ }^{1}$ \\ ${ }^{1}$ Instituto de Ciências da Atividade Física e Esportes, Universidade Cruzeiro do Sul, Rua Galvão Bueno 868, \\ $13^{\circ}$ Andar, Bloco B, 01506-000 Liberdade, São Paulo, SP, Brazil \\ ${ }^{2}$ Department of Physiology and Biophysics, Institute of Biomedical Sciences, University of São Paulo, \\ Avenida Lineu Prestes 1524, 05508-900 São Paulo, SP, Brazil
}

Correspondence should be addressed to Elaine Hatanaka; ehata@usp.br

Received 25 September 2013; Revised 31 December 2013; Accepted 13 January 2014; Published 20 February 2014

Academic Editor: Jonathan Peake

Copyright (C) 2014 Leandro da Silva Borges et al. This is an open access article distributed under the Creative Commons Attribution License, which permits unrestricted use, distribution, and reproduction in any medium, provided the original work is properly cited.

\begin{abstract}
Herein, we investigated the effects of a ballet class on the kinetic profiles of creatine kinase (CK) and lactate dehydrogenase (LDH) activities, cytokines, complement component 3 (C3), and the concentrations of immunoglobulin (Ig), $\operatorname{IgA}$ and $\operatorname{IgM}$, in ballerinas. We also verified neutrophil death and ROS release. Blood samples were taken from 13 dancers before, immediately after, and 18 hours after a ballet class. The ballet class increased the plasma activities of CK-total (2.0-fold) immediately after class, while the activities of CK-cardiac muscle (1.0-fold) and LDH (3.0-fold) were observed to increase 18 hours after the class. Levels of the TNF- $\alpha$, IL-1 $\beta$, $\operatorname{IgG}$, and IgA were not affected under the study conditions. The exercise was found to induce neutrophil apoptosis (6.0-fold) 18 hours after the ballet class. Additionally, immediately after the ballet class, the neutrophils from the ballerinas were found to be less responsive to PMA stimulus. Conclusion. Ballet class was found to result in inflammation in dancers. The inflammation caused by the ballet class remained for 18 hours after the exercise. These findings are important in preventing the development of chronic lesions that are commonly observed in dancers, such as those with arthritis and synovitis.
\end{abstract}

\section{Introduction}

Classical ballet is an art that requires daily practice, dedication, and effort to produce light, graceful, and beautiful movements. Dancing has been found to improve motor control, attention, and physical fitness; however, studies have pointed to the intense training as a triggering factor for acute and chronic injuries in dancers [1-3]. Acute and chronic lesions consisting of osteochondral stress, nonstress fractures in the lower extremities and feet, and degenerative arthritis of multiple joints have been reported in ballerinas [4]. The search for perfection by aesthetic standards, coupled with the desire for total control of body movements, compels the dancer to exceed the body's natural limitations, thereby potentially resulting in lesions. Additionally, the body positions in classical ballet are contrary to natural anatomical tendencies and may generate joint misalignments in ballerinas.

Although classical ballet is a widely known and practiced art, there have only been a few limited studies on the physiological and immunological consequences imparted by this kind of dance and the resulting implications on dancers' health. Currently, it is thought that intense exercise accompanied by chronic inflammation may contribute to the appearance of health complications in ballerinas. Studies point to the negative role of inflammation in the progression of inflammatory complications, such as arthritis and arthrosis $[5,6]$. Hence, searching for good serum markers of lesions and inflammation that appear during physical exertion may be an important strategy to establish appropriate exercise intensity for ballerinas. Additionally, it is important to establish the amount of time required for ballerinas to 
recover from exercise-related tissue damage, thereby avoiding chronic inflammation.

Dancing can result in muscle injury, which promotes release of the skeletal muscle enzymes CK and LDH. Both $\mathrm{CK}$ and $\mathrm{LDH}$ are found in the cytosol; thus, the appearance of these enzymes in the serum indicates muscular lesion [79]. The inflammatory response to cellular lesions is initiated by the infiltration of fluid, plasma proteins, and neutrophils into the injured tissue. Cytokines (e.g., TNF- $\alpha$, IL- $1 \beta$, and interleukin-6 [IL-6]) are mediators that participate in the onset of the inflammatory response [10-12]. However, when inflammation and/or strenuous exercise are prolonged, the initial inflammatory response results in the production of hormones related to stress and anti-inflammatory cytokines, such as IL-4, which decrease immunoglobulin (IgA and IgM) concentrations. This may then lead to immunosuppression and a heightened susceptibility to invasive microorganisms, which can negatively affect dancers' performance. Another important point to be considered is the association of exercise-induced muscle damage with neutrophil infiltration into the muscle, thereby resulting in the production of ROS and a systemic elevation in the production of cytokines and other inflammatory mediators and cellular necrosis. Activated neutrophils are a common finding in chronic inflammation $[13,14]$.

We hypothesized that dancing could expose the dancers to chronic inflammation with reactive neutrophils, which may then lead to the onset of joint problems. This study determined the effects of a ballet class on the levels of TNF$\alpha$, IL- $1 \beta$, IL-6, IgA, IgG, and C3 in blood samples from the dancers. The proportion of necrotic (loss of plasma membrane integrity) to apoptotic (DNA fragmentation) neutrophils was evaluated. We also analyzed the release of ROS by neutrophils under basal and stimulated conditions. All parameters were assessed before and immediately after the ballet exercise and then 18 hours thereafter.

\section{Materials and Methods}

2.1. Materials. RPMI-1640 medium, HEPES, penicillin, and streptomycin were purchased from Invitrogen (Carlsbad, CA, USA). Hydroethidine, Histopaque 1077, PMA (phorbol myristate acetate), LPS (lipopolysaccharide), Triton X-100, and propidium iodide were supplied by Sigma Chemical Co. (St. Louis, MO). Hydroethidine and PMA were dissolved in DMSO (dimethyl sulfoxide). The final concentration of DMSO in the assay medium did not exceed $0.01 \%$. A preliminary experiment showed that DMSO at this concentration is not toxic for neutrophils and does not interfere in the results obtained [15]. Reagents, water, and plastic wares used in the experiments were all endotoxin-free.

2.2. Subjects. With the approval of the Ethics Committee of Cruzeiro do Sul University (115/2009), 13 women volunteers participated in the study. All of the ballerinas signed an informed consent form agreeing to submit to the procedures involved in the study. The group had the following characteristics (mean \pm SE): age $20.0 \pm 0.8$ years, body mass $41.4 \pm$ $1.6 \mathrm{~kg}$, height $1.6 \pm 0.0 \mathrm{~m}$, body fat $24.0 \pm 1.3 \%, \mathrm{VO}_{2 \text { peak }} 36.8 \pm$
$2.9 \mathrm{~mL} \cdot \mathrm{kg}^{-1} \cdot \mathrm{min}^{-1}$, and sports experience of $7.0 \pm 1.5$ years. The ballerinas used to dance 4-6 hours, five days of the week and rest in the weekend. The participants had rested for 72 hours before the ballet class. All the participants danced for 70 minutes, according to a protocol established by Guidetti et al. [16].

The analysis of the ballet dancers' physical and metabolic profiles through the assessments of blood pressure, heart rate, blood glucose, and muscle strength testing revealed no differences in the dancers before, immediately after, and 18 hours after a ballet class (data not shown). Participants with histories of infection, viruses, chronic lesions, diabetes, rheumatoid arthritis, hormonal dysfunction, lupus, or other inflammatory and hematology diseases (such as hemoglobinopathies) and who were taking medication were excluded from the study.

2.3. Sample Collection. Twenty milliliters of venous blood was collected before, immediately after, and 18 hours after a ballet class. The blood samples were drawn from one of three main veins at the antecubital fossa (the cephalic, basilic, and median cubitals). In each case, the vein was chosen based on the identification of an optimal site by both visual and tactile exploration. The blood samples were drawn into two $\mathrm{BD}$ vacutainer tubes, with the first containing heparin, which was used for plasma collection and cell separation; the second was a dry gel tube for serum collection. After collecting the samples, the blood was centrifuged $(400 \times \mathrm{g}$, 10 minutes), and the serum and plasma were separated from the cell components. Neutrophils were immediately isolated, and cellular function was tested. The enzymatic activities of $\mathrm{CK}$ and $\mathrm{LDH}$ were measured not later than 48 hours after the collection of the plasma. Whenever necessary, the samples were diluted to fall within the linear range of the methods. All of the dilutions were performed with suitable dilution reagents, according to the instructions of the kit manufacturer (DuoSet Kit: Quantikine, R\&D System, Minneapolis, MN, USA). The concentrations of diluted samples were determined after multiplying the reported values by the dilution factor.

Plasma was collected and stored at $-80^{\circ} \mathrm{C}$ prior to cytokine determination by ELISA. The samples were stored for no longer than 3 months.

2.4. Determination of Creatine Kinase (CK) and Lactate Dehydrogenase (LDH) Activities. Serum CK and LDH activities were measured according to the methods established by Zammit and Newsholme [17]. The kits were supplied by Bioclin Diagnostics (São Paulo, SP, Brazil), and the measurements were performed according to the manufacturer's instructions. The control serum was used to check the accuracy and precision of the assay, with a maximum error of $5 \%$.

2.5. Determination of Plasma Cytokines. Plasma levels of IL- $1 \beta$, TNF- $\alpha$, IL- 6 , and IL-10 were determined by ELISA, according to the manufacturer's instructions (DuoSet Kit: Quantikine, R\&D System, Minneapolis, MN, USA). The IL6 and IL-10 methods were linear for protein concentrations in the ranges of 25 picograms per milliliter $(\mathrm{pg} / \mathrm{mL})$ to 
$600 \mathrm{pg} / \mathrm{mL}$ and $25 \mathrm{pg} / \mathrm{mL}$ to $2000 \mathrm{pg} / \mathrm{mL}$, respectively. The TNF- $\alpha$ method was considered to be linear for protein concentrations in the range of $6.0 \mathrm{pg} / \mathrm{mL}$ to $1000 \mathrm{pg} / \mathrm{mL}$; for IL- $\beta$, the range was $5.0 \mathrm{pg} / \mathrm{mL}$ to $250 \mathrm{pg} / \mathrm{mL}$. A standard curve was built for each set of samples, and the cytokines were assayed, yielding a correlation coefficient in the range of 0.98 to 0.99 . For these determinations, the intra-assay coefficient of variance was $3-5 \%$, while the interassay coefficient of variance was $8-10 \%$.

2.6. Cell Purification. The experiments were performed within $1 \mathrm{~h}$ of venipuncture. Human neutrophil (>98\%) preparations were isolated from the peripheral blood of human donors under endotoxin-free conditions using Histopaque 1077 (Sigma Chemical Co., St. Louis, MO) according to the manufacturer's instructions. Briefly, blood was diluted v/v with $10 \mathrm{mM}$ PBS Dulbecco at pH 7.4 and carefully layered on $10 \mathrm{~mL}$ of a commercial gradient of Ficoll-Hypaque (Histopaque, $d=1.077$ ). The tube was centrifuged at $400 \mathrm{~g}$ at room temperature for $20 \mathrm{~min}$. The supernatant, rich in mononuclear cells, was discarded, and $10 \mathrm{~mL}$ of $5 \%$ dextran was added to the pellet. The tube was homogenized and maintained for $45 \mathrm{~min}$ on ice to allow erythrocyte sedimentation. The resulting supernatant, rich in granulocytes, was recovered, washed with PBS Dulbecco, and the pellet submitted to hypotonic treatment with $10 \mathrm{~mL}$ of distilled water to promote lysis of contaminated erythrocytes. After $1 \mathrm{~min}$, the isotonicity was restored by the addition of $5 \mathrm{~mL}$ of $2.7 \% \mathrm{NaCl}$ and $15 \mathrm{~mL}$ of PBS Dulbecco. Cells were centrifuged at $400 \mathrm{~g}$ for $5 \mathrm{~min}$ at room temperature and suspended in RPMI 1640 medium. The purity of the cell preparation was higher than $98 \%$.

2.7. Cell Viability Assay (Proportion of Necrotic Cells). Neutrophil viability was assessed using a FACSCalibur Cytometer (Becton Dickinson Systems, CA, USA). The percentage of viable cells in each sample was determined based on propidium iodide staining $(0.05 \% \mathrm{w} / \mathrm{v}$ solution in PBS $)$. Ten thousand events were analyzed per sample. Fluorescence of the propidium iodide was measured using the FL2 channel (orange-red fluorescence $=585 / 545 \mathrm{~nm}$ ) [18] .

2.8. Proportion of Cells with DNA Fragmentation. DNA fragmentation was analyzed by flow cytometry after DNA staining with propidium iodide (Sigma Chemical Co., St. Louis, MO). The presence of detergent in the solution permeabilized the cells, which promptly incorporated the dye into DNA. After incubation, the cells were centrifuged at $1000 \times \mathrm{g}$ for $15 \mathrm{~min}$ at $4^{\circ} \mathrm{C}$. The resulting pellets were carefully resuspended in $300 \mu \mathrm{L}$ hypotonic solution containing $50 \mu \mathrm{g} / \mathrm{mL}$ propidium iodide, $0.1 \%$ sodium citrate, and $0.1 \%$ Triton X-100. The cells were then incubated for $30 \mathrm{~min}$ at $4^{\circ} \mathrm{C}$. Ten thousand events were analyzed per sample. Fluorescence of the propidium iodide was measured using the FL2 channel (orange-red fluorescence $=585 / 545 \mathrm{~nm}$ ) [18].

2.9. Flow Cytometric Measurement of Reactive Oxygen Metabolites Using Hydroethidine. Hydroethidine $(1 \mu \mathrm{M})$ was added to the neutrophil $\left(2.5 \times 10^{6}\right.$ cells $\left./ \mathrm{mL}\right)$ incubation medium when required. Immediately afterwards, the cells were treated with PMA $(54 \mathrm{ng} / \mathrm{mL})$. ROS release was monitored for 30 minutes. The assays were run in PBS buffer supplemented with $\mathrm{CaCl}_{2}(1 \mathrm{mM}), \mathrm{MgCl}_{2}(1.5 \mathrm{mM})$, and glucose $(10 \mathrm{mM})$ at $37^{\circ} \mathrm{C}$ in a final volume of $0.3 \mathrm{~mL}$. Hydroethidine (HE) has been widely used for the flow cytometric measurement of intracellular ROS production. Hydroethidine, a reduced derivative of ethidium bromide, easily penetrates into the cells and shows weak fluorescence weakly when excited by light at $480 \mathrm{~nm}$ wavelength. Hydroethidine is intracellularly oxidised by oxygen radicals, being converted into ethidium bromide that tightly binds to DNA and shows a strong red fluorescence that was measured using the FL3 channel of a FACSCalibur flow cytometer (Becton Dickinson, CA, USA). Ten thousand events were analyzed per experiment $[15,18]$.

2.10. Externalization of Phosphatidylserine. The externalization of phosphatidylserine was analysed by flow cytometry after PS staining with annexin V-FITC. Annexin V is a phospholipid-binding protein that has a high affinity for PS. PI is used to distinguish viable from nonviable cells. Fluorescence of annexin V-FITC was measured as described above in FL1 channel (green fluorescence; 530/30 nm) and PI in FL2 channel (orange/red fluorescence; 585/545 nm).

2.11. Determination of the MTP (Mitochondrial Transmembrane Potential). Cells were centrifuged at $1000 \mathrm{~g}$ for $10 \mathrm{~min}$ at $4^{\circ} \mathrm{C}$, and the pellet was resuspended in $500 \mu \mathrm{L}$ of PBS. Rhodamine 123 (Sigma Chemical Co., St. Louis, MO) is a cellpermeant cationic fluorescent dye that is readily sequestered by active mitochondria without inducing cytotoxic effects. Rhodamine $123(5 \mu \mathrm{mol} / \mathrm{L})$ was added and the cells were then incubated for $15 \mathrm{~min}$ in the dark. Cells were washed twice with ice-cold PBS and incubated for $30 \mathrm{~min}$ in the dark. Fluorescence was determined by flow cytometry using the FL1 channel (green fluorescence; 530/30 nm) as described above.

2.12. Statistical Analysis. The values are presented as the means \pm standard errors of 13 ballerinas. The statistical analysis consisted of one-way analysis of variance (ANOVA) using the post-hoc Student-Newman-Keuls Multiple Comparison test (INStat; Graph Pad Software, San Diego, CA, USA). The significance level was set at $P<0.05$. The degree of linear relationship between $\mathrm{CK}$ and $\mathrm{LDH}$ variables was established by Pearson's correlation.

\section{Results}

3.1. Effect of a Classical Ballet Class on Markers of Muscle Damage. Figure 1 shows the variations of CK-NAC, CK-MB, and $\mathrm{LDH}$ in the blood of ballet dancers immediately after and 18 hours following a classical ballet class. We observed a significant increase in the activity of CK-NAC (2.0-fold, $P<0.05)$ immediately after and 18 hours after the ballet class (2.0-fold, $P<0.05)$ (Figure 1(a)). Plasma activities of CK-MB (1.0-fold, $P<0.05$ ) (Figure 1(b)) and LDH (3.0-fold, $P<0.05$ ) (Figure 1(c)) were also observed to increase in the 18-hour period following the class. Figures 1(a), 1(b), and 1(c) 


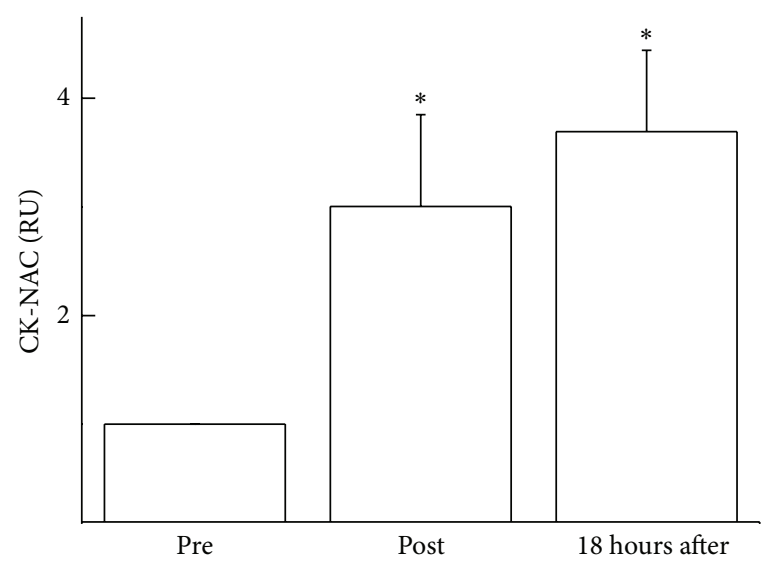

(a)

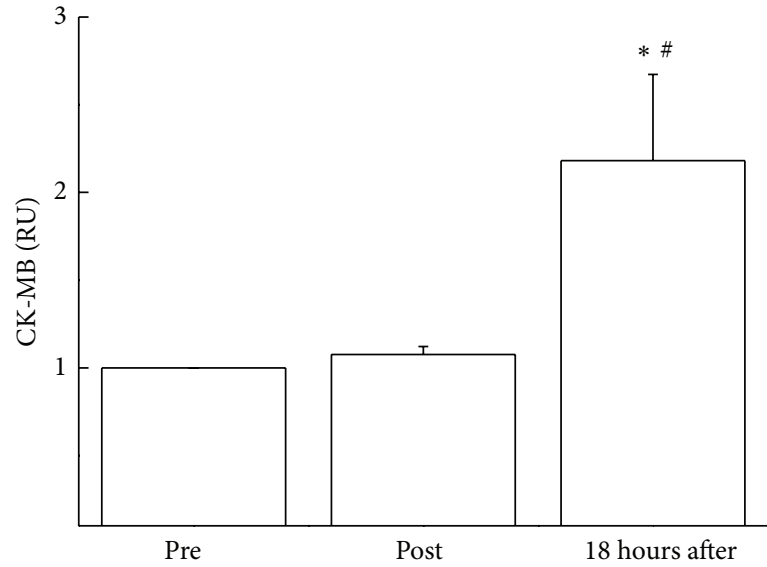

(b)

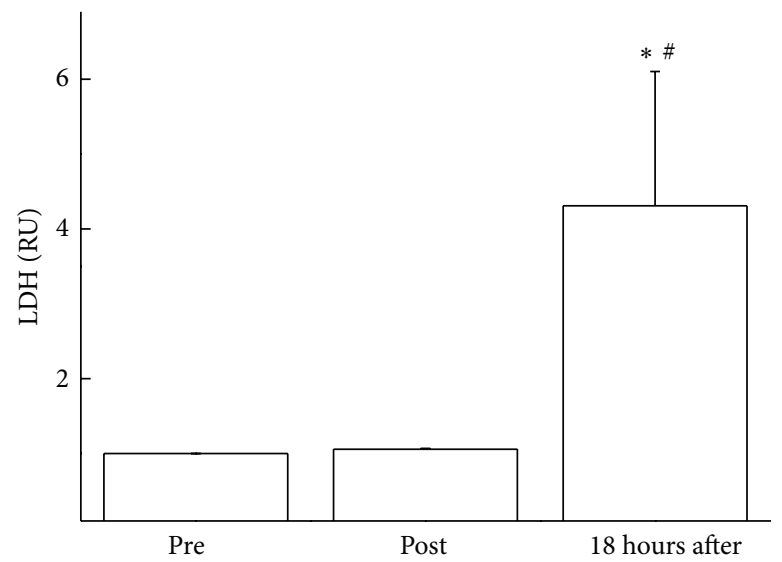

(c)

FIGURE 1: Effect of classical ballet on muscle lesion markers. Serum concentrations of CK-NAC (a), CK-MB (b), and LDH (c) in dancers were determined before, immediately after, and 18 hours after a ballet class. The values are presented as mean \pm standard error of 13 dancers and are presented as relative unit (UR). Figures were plotted with the data of the variations in markers during a ballet class, thus indicating the normalization between the values of before and after a ballet class. ${ }^{*} P<0.05$ for comparison to preclass condition and ${ }^{\#} P<0.05$ for comparison to immediately after ballet class condition.

were plotted with the data of the variations in markers during a ballet class, thus indicating the normalization between the values of before and after a ballet class. The values are presented as relative unit (RU).

\subsection{Effect of a Classical Ballet Class on Inflammatory Markers.} Under the study conditions, a decrease in the concentration of IL-4 (3.0-fold, $P<0.05)$ was also noted 18 hours after the class (Table 1). No significant differences were identified in the blood concentrations of IL- $1 \beta$, TNF- $\alpha$, IL-6, IL-10, IL-2, C3, IgA, and IgG (Table 1).

\subsection{Effect of a Classical Ballet Class on Death and Functionality} of Neutrophils. We noted a significant increase in the mean number of neutrophils with fragmented DNA at 18 hours after the class (6-fold, $P<0.05$ ) (Figure 2 ). The neutrophil analysis did not reveal any significant changes in the number of cells, cell membrane integrity, externalization of phosphatidylserine, or mitochondrial depolarization (Table 2).
As shown in Figure 3, we identified changes in neutrophil function from ballerinas immediately following a classical ballet class and found that neutrophils were less responsive to PMA stimuli.

\section{Discussion}

A number of factors are thought to contribute to injuries among ballerinas, including the young age at which intensive dance training begins, dancing en pointe, antianatomical body positions, unusual dietary regimens, and emotional stress. In fact, in ballerinas, the most important cause of increased arthritis and arthrosis may be partially explained by repetitive microtrauma that results in chronic inflammation $[19,20]$. Thus, prevention studies are required to reduce the incidence, severity and cost of ballerina injuries. Moreover, while dance injuries have been the target of numerous studies, we have not identified any studies in the literature describing the relationship of injuries to the immune system 
TABLE 1: Effects of classical ballet class on the serum concentrations of IL- $1 \beta$, TNF- $\alpha$, IL-6, IL-10, IL-2, IL- 4 and C3 were quantified in the plasma, and serum concentrations of IgA and IgG were quantified in the serum of dancers before, immediately after and 18 hours after a ballet class.

\begin{tabular}{lccc}
\hline & Before & After & 18 hours after \\
\hline IL-1 $\beta(\mathrm{ng} / \mathrm{mL})$ & $0.29 \pm 0.08$ & $0.25 \pm 0.06$ & $0.23 \pm 0.06$ \\
TNF- $\alpha(\mathrm{ng} / \mathrm{mL})$ & $0.16 \pm 0.04$ & $0.15 \pm 0.04$ & $0.12 \pm 0.01$ \\
IL-6 $(\mathrm{ng} / \mathrm{mL})$ & $0.11 \pm 0.03$ & $0.13 \pm 0.03$ & $0.08 \pm 0.02$ \\
IL-10 $(\mathrm{ng} / \mathrm{mL})$ & $0.12 \pm 0.01$ & $0.12 \pm 0.01$ & $0.13 \pm 0.01$ \\
IL-2 $(\mathrm{ng} / \mathrm{mL})$ & $0.04 \pm 0.005$ & $0.04 \pm 0.005$ & $0.02 \pm 0.02$ \\
IL-4 $(\mathrm{ng} / \mathrm{mL})$ & $88.00 \pm 1.00$ & $86.85 \pm 1.93$ & $81.74 \pm 0.74^{*}$ \\
IgA $(\mathrm{mg} / \mathrm{dL})$ & $198 \pm 13$ & $185 \pm 17$ & $196 \pm 13$ \\
IgG $(\mathrm{mg} / \mathrm{dL})$ & $27 \pm 3$ & $29 \pm 3$ & $33 \pm 3$ \\
C3 $(\mathrm{mg} / \mathrm{dL})$ & $219 \pm 0.87$ & $218 \pm 2.00$ & $219 \pm 2.55$ \\
\hline
\end{tabular}

The values are presented as the means \pm standard errors of 13 dancers. $\mathrm{mg} / \mathrm{dL}$ : milligrams per deciliter. ${ }^{*} P<0.05$ for comparison to pre-class conditions.

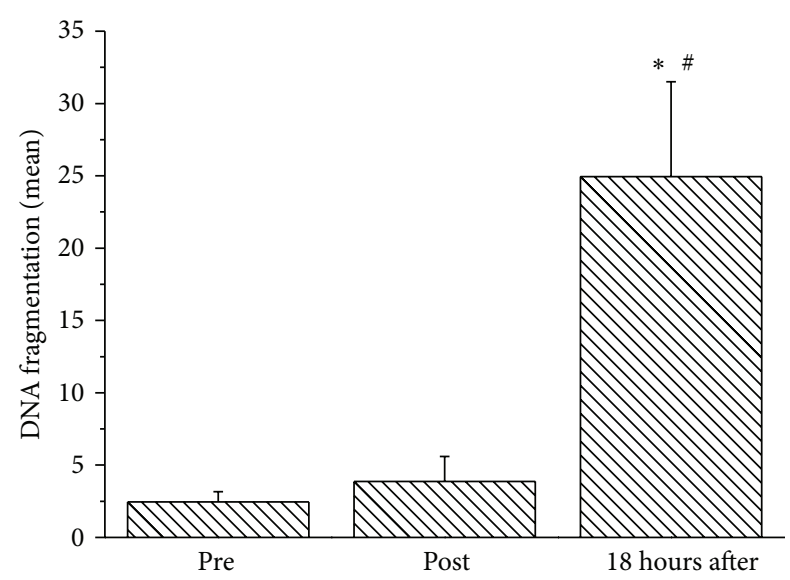

FIGURE 2: Neutrophil DNA fragmentation (\%) in ballet dancers determined before, immediately after, and 18 hours after a ballet class. The values are presented as the mean \pm standard error of 13 dancers. ${ }^{*} P<0.05$ for comparison to preclass and ${ }^{\#} P<0.05$ for comparison to immediately after ballet class.

that specifically relate ballet lesions, inflammation, and biochemical/immunological markers.

Our results demonstrated that a simple ballet class increased the plasma activities of the muscle enzymes CK and LDH and decreased the concentration of the antiinflammatory cytokine IL- 4 . In addition, 18 hours after the class, signs of muscular lesions, neutrophil necrosis, and decreased levels of anti-inflammatory cytokines all pointed to a subclinical inflammatory condition. TNF- $\alpha$, IL-1 $\beta$, IgG, and IgA blood levels were not affected in the conditions studied.

One day following a classical ballet class, the ballerinas exhibited a significant increase in the mean number of neutrophils with fragmented DNA. Apoptosis is now known as an active cell death process that is characterized by the activation of proteases, autodestruction of chromatin (DNA fragmentation), nuclear condensation, cellular membrane blebbing, and vascularization of internal components.

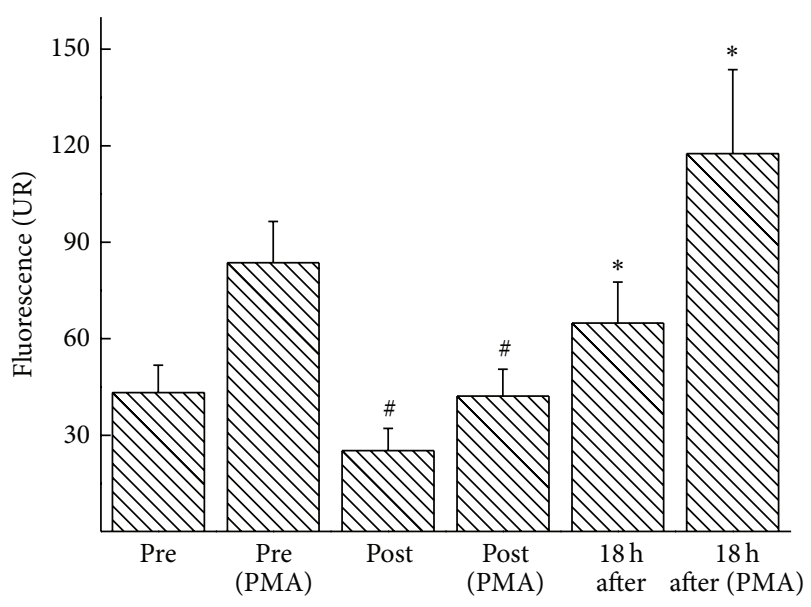

FIGURE 3: ROS release by neutrophils in ballet dancers was determined before, immediately after, and 18 hours after a ballet class. The measurements were performed under basal and PMA-stimulated conditions. The values are presented as the means \pm standard errors of 13 dancers.

Our group has demonstrated that professional athletes participating in an adventure race [21] and triathlon present leukocyte death after the competition $[22,23]$. While the stress associated with acute exercise has been reported to induce significant leukocyte apoptosis, not all investigations have confirmed this finding, and the mechanism behind exercise-induced apoptosis remains unclear. Some hypotheses suggest the following: (i) the elimination of excessive cells that appear during exercise is a physiological response; (ii) normal regulatory processes that serve to remove certain damaged cells do so without a pronounced inflammatory response; (iii) apoptosis is the body's response to excessive oxidative stress; (iv) increases in cytokines such as TNF- $\alpha$ serve as important signaling molecules in apoptotic and other signaling pathways $[24,25]$.

Neutrophils are the first cells to migrate to the site of injury and are responsible for local cleaning, phagocytosing pathogens, and removing cellular debris. The initial release of proinflammatory mediators and ROS and the activation of neutrophils are important events of tissue repair; however, the inflammatory response must be a self-controlled event [26-29]. The hypoproduction of ROS by neutrophils that come into contact with stimuli may lead to increased susceptibility to invasive microorganisms, thereby impairing the dancers' performance and health. In these aspects, our results demonstrated that neutrophils are less responsive to PMA stimuli immediately after a ballet class. These results point to the reduced efficiency of neutrophils against infection when exposed to pathogens immediately after a ballet class.

Chronic inflammation is characterized by influxes of neutrophils at sites of inflammation and may be the main factor involved in the development of arthritis, arthrosis, and other inflammatory joint diseases that have been observed in ballerinas (Figure 4). Experimental data indicates that neutrophils play an important role in both the immunization and the effector phases of autoimmune diseases, such as arthritis. 
TABLE 2: Effects of a classical ballet class on neutrophil numbers, membrane integrity, externalization of phosphatidylserine and mitochondrial depolarization before, immediately after and 18 hours after a ballet class.

\begin{tabular}{lccc}
\hline Neutrophils & Before & After & 18 hours after \\
\hline Number of Neutrophils $\left(\times 10^{6}\right)$ & $41.83 \pm 8.89$ & $48.5 \pm 19.72$ & $26.66 \pm 8.38$ \\
Cell Membrane Integrity (mean) & $63.95 \pm 14.21$ & $53.92 \pm 15.07$ & $53.70 \pm 14.32$ \\
Externalization of Phosphatidylserine (mean) & $11.14 \pm 3.30$ & $9.77 \pm 4.31$ & $6.17 \pm 2.58$ \\
Mitochondrial Depolarization (mean) & $114.94 \pm 11.31$ & $121.50 \pm 11.69$ & $155.23 \pm 31.62$ \\
\hline
\end{tabular}

The values are presented as the means \pm standard errors of 13 dancers. ${ }^{*} P<0.05$ for comparison to pre-class conditions.

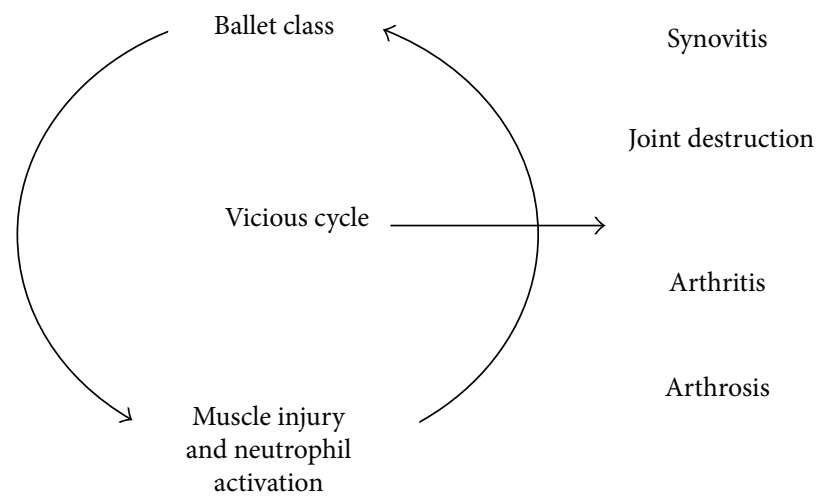

FIgURE 4: Chronic inflammations as a result of ballet dancing class causes subclinical systemic inflammation and the activation of the function of neutrophils in the chronic inflammation may be the main factor involved in the genesis of arthritis and other inflammatory joint diseases in ballerinas.

The fact that neutrophils are involved in autoantibodyinduced arthritis indicates that these cells contribute to the autoantibody-mediated component of the disease's effector phase. Neutrophils appear to be required for the extravasation and deposition of autoantibodies at the joints [30].

Other neutrophil analyses demonstrated no significant changes in the number of cells, cell membrane integrity, externalization of phosphatidylserine, and mitochondrial depolarization.

The mechanical stressors on joints arise from many sources, including misalignments of bones caused by antianatomical ballet positions, mechanical injury, overtraining, or jumps that overstress joints and result in local inflammation. Chronic inflammation as a result of a nonperiodized resting period results in constant activation of the immune system and may be dangerous for the dancers' health.

\section{Conclusions}

In summary, we have found that immediately after a ballet class, neutrophils from ballerinas were found to be less responsive to stimuli, thereby pointing to a transient immunosuppression. Eighteen hours after the class, signs of muscular lesion, neutrophil necrosis, and decreased levels of anti-inflammatory cytokines were observed in the ballerinas, thereby suggesting a persistent inflammatory condition. These findings may represent an extremely useful tool to design new studies and strategies to protect dancers against microorganism infection as a result of transient immunosuppression immediately following the class and to prevent dancers performance from declining as a result of chronic inflammation.

\section{Conflict of Interests}

The authors declare that there is no conflict of interests regarding the publication of this paper.

\section{Acknowledgments}

The authors are indebted to Sabrina da Silva Moura and Valéria Gomes Campos Silva for their technical assistance. This research was supported by the Brazilian research funding agencies FAPESP (São Paulo Research Foundation) (Process nos. 2010/04005-9 and 2011/21441-0) and CNPq (National Council for Scientific and Technological Development) (Process no. 121641/2009-0). The authors also thank the volunteers for providing the samples used in this work.

\section{References}

[1] J. K. Strassel, D. C. Cherkin, L. Steuten, K. J. Sherman, and H. J. M. Vrijhoef, "A systematic review of the evidence for the effectiveness of dance therapy," Alternative Therapies in Health and Medicine, vol. 17, no. 3, pp. 50-59, 2011.

[2] J. W. L. Keogh, A. Kilding, P. Pidgeon, L. Ashley, and D. Gillis, "Physical benefits of dancing for healthy older adults: a review," Journal of Aging and Physical Activity, vol. 17, no. 4, pp. 479-500, 2009.

[3] K. Khan, J. Brown, S. Way et al., "Overuse injuries in classical ballet,” Sports Medicine, vol. 19, no. 5, pp. 341-357, 1995.

[4] J. C. Hillier, K. Peace, A. Hulme, and J. C. Healy, "MRI features of foot and ankle injuries in ballet dancers," British Journal of Radiology, vol. 77, no. 918, pp. 532-537, 2004.

[5] S. Ritter and M. Moore, "The relationship between lateral ankle sprain and ankle tendinitis in ballet dancers," Journal of Dance Medicine \& Science, vol. 12, no. 1, pp. 23-31, 2008.

[6] P. Libby, "Role of inflammation in atherosclerosis associated with rheumatoid arthritis," American Journal of Medicine, vol. 121, no. 10, pp. S21-S31, 2008.

[7] P. Brancaccio, N. Maffulli, and F. M. Limongelli, "Creatine kinase monitoring in sport medicine," British Medical Bulletin, vol. 81-82, no. 1, pp. 209-230, 2007.

[8] P. Brancaccio, N. Maffulli, R. Buonauro, and F. M. Limongelli, "Serum Enzyme Monitoring in Sports Medicine," Clinics in Sports Medicine, vol. 27, no. 1, pp. 1-18, 2008. 
[9] B. Gojanovic, F. Feihl, G. Gremion, and B. Waeber, "Muscle enzyme activity and exercise," Praxis, vol. 98, no. 3, pp. 133-139, 2009.

[10] A. H. Sprague and R. A. Khalil, "Inflammatory cytokines in vascular dysfunction and vascular disease," Biochemical Pharmacology, vol. 78, no. 6, pp. 539-552, 2009.

[11] G. van Hall, "Cytokines: muscle protein and amino acid metabolism," Current Opinion in Clinical Nutrition and Metabolic Care, vol. 15, no. 1, pp. 85-91, 2012.

[12] A. M. W. Petersen and B. K. Pedersen, "The anti-inflammatory effect of exercise," Journal of Applied Physiology, vol. 98, no. 4, pp. 1154-1162, 2005.

[13] A. Mantovani, M. A. Cassatella, C. Costantini, and S. Jaillon, "Neutrophils in the activation and regulation of innate and adaptive immunity," Nature Reviews Immunology, vol. 11, no. 8, pp. 519-531, 2011.

[14] J. Peake and K. Suzuki, "Neutrophil activation, antioxidant supplements and exercise-induced oxidative stress," Exercise Immunology Review, vol. 10, pp. 129-141, 2004.

[15] E. Hatanaka, A. C. Levada-Pires, T. C. Pithon-Curi, and R. Curi, "Systematic study on ROS production induced by oleic, linoleic, and $\gamma$-linolenic acids in human and rat neutrophils," Free Radical Biology and Medicine, vol. 41, no. 7, pp. 1124-1132, 2006.

[16] L. Guidetti, M. C. Gallotta, G. P. Emerenziani, and C. Baldari, "Exercise intensities during a ballet lesson in female adolescents with different technical ability," International Journal of Sports Medicine, vol. 28, no. 9, pp. 736-742, 2007.

[17] V. A. Zammit and E. A. Newsholme, "The maximum activities of hexokinase and other enzymes in relation to carbohydrate utilization in muscles from marine invertebrates," Biochemical Journal, vol. 160, no. 3, pp. 447-462, 1976.

[18] N. R. de Moura, M. F. Cury-Boaventura, V. C. Santos et al., "Inflammatory response and neutrophil functions in players after a futsal match," Journal of Strength \& Conditioning Research, vol. 26, no. 9, pp. 2507-2514, 2012.

[19] E. H. Miller, H. J. Schneider, J. L. Bronson, and D. McLain, “A new consideration in athletic injuries. The classical ballet dancer," Clinical Orthopaedics and Related Research, vol. 111, pp. 181191, 1975.

[20] M. L. Kvartsakhava, V. P. Saakadze, M. P. Tsimakuridze, D. G. Zurashvili, and N. A. Khachapuridze, "Health peculiarities among georgian national ballet dancers," Georgian Medical News, no. 136, pp. 121-124, 2006.

[21] A. C. Levada-Pires, C. E. R. Fonseca, E. Hatanaka et al., "The effect of an adventure race on lymphocyte and neutrophil death," European Journal of Applied Physiology, vol. 109, no. 3, pp. 447-453, 2010.

[22] A. C. Levada-Pires, M. F. Cury-Boaventura, R. Gorjão et al., "Neutrophil death induced by a triathlon competition in elite athletes," Medicine and Science in Sports and Exercise, vol. 40, no. 8, pp. 1447-1454, 2008.

[23] A. C. Levada-Pires, M. F. Cury-Boaventura, R. Gorjão et al., "Induction of lymphocyte death by short- and long-duration triathlon competitions," Medicine and Science in Sports and Exercise, vol. 41, no. 10, pp. 1896-1901, 2009.

[24] S. Phaneuf and C. Leeuwenburgh, "Apoptosis and exercise," Medicine and Science in Sports and Exercise, vol. 33, no. 3, pp. 393-396, 2001.

[25] J. Quadrilatero, S. E. Alway, and E. Dupont-Versteegden, "Skeletal muscle apoptotic response to physical activity: potential mechanisms for protection," Applied Physiology, Nutrition and Metabolism, vol. 36, no. 5, pp. 608-617, 2011.

[26] D. W. Gilroy, "Eicosanoids and the endogenous control of acute inflammatory resolution," International Journal of Biochemistry and Cell Biology, vol. 42, no. 4, pp. 524-528, 2010.

[27] V. Kumar, "Homeostatic control of immunity by TCR peptidespecific Tregs," Journal of Clinical Investigation, vol. 114, no. 9, pp. 1222-1226, 2004.

[28] M. Kubo and Y. Motomura, "Transcriptional regulation of the anti-inflammatory cytokine IL-10 in acquired immune cells," Frontiers in Immunology, vol. 3, article 275, 2012.

[29] K. Suzuki, M. Totsuka, S. Nakaji et al., "Endurance exercise causes interaction among stress hormones, cytokines, neutrophil dynamics, and muscle damage," Journal of Applied Physiology, vol. 87, no. 4, pp. 1360-1367, 1999.

[30] T. Németh and A. Mócsai, "The role of neutrophils in autoimmune diseases," Immunology Letters, vol. 143, no. 1, pp. 9-19, 2012. 


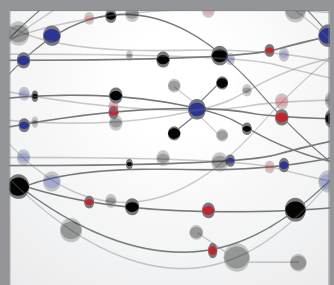

The Scientific World Journal
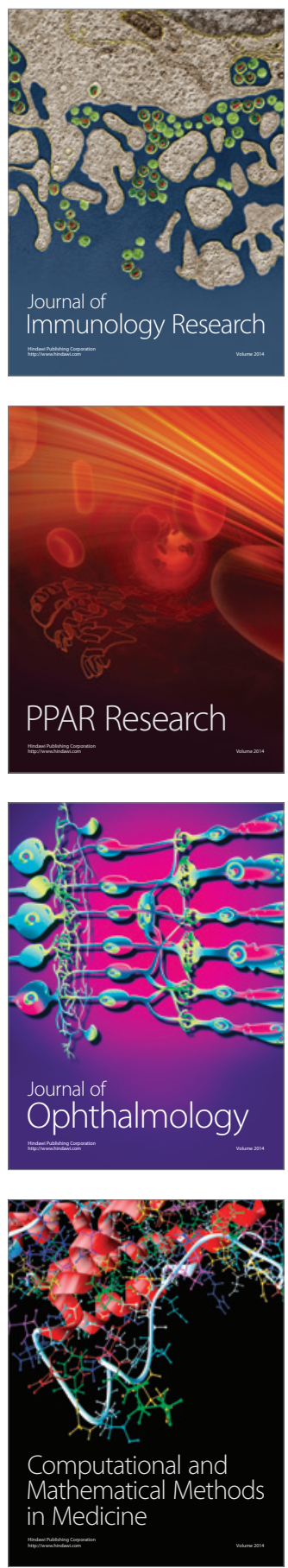

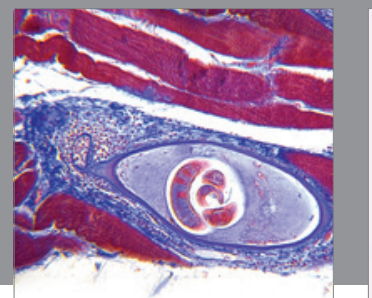

Gastroenterology

Research and Practice
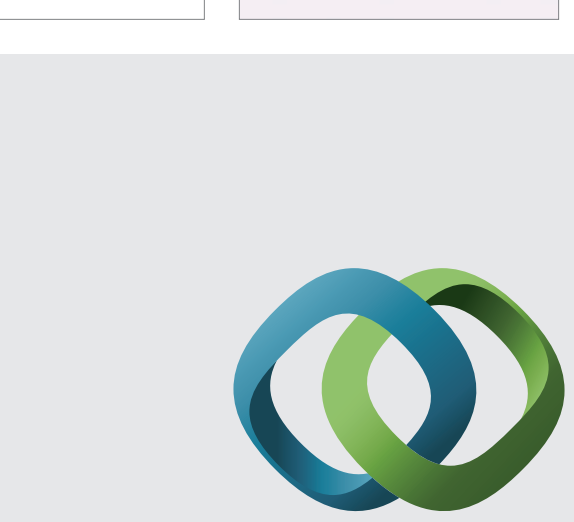

\section{Hindawi}

Submit your manuscripts at

http://www.hindawi.com
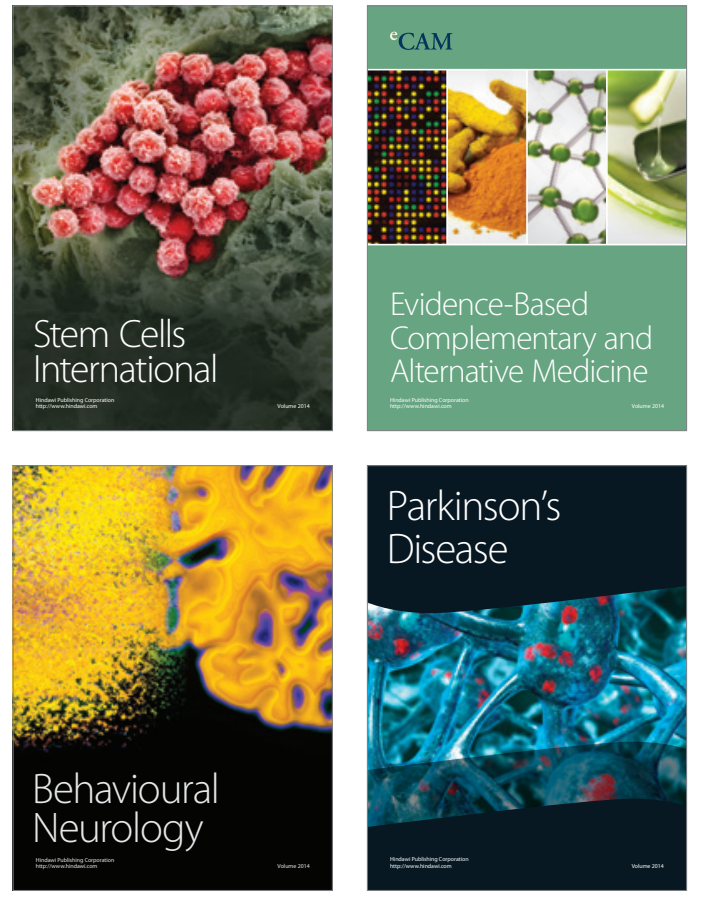
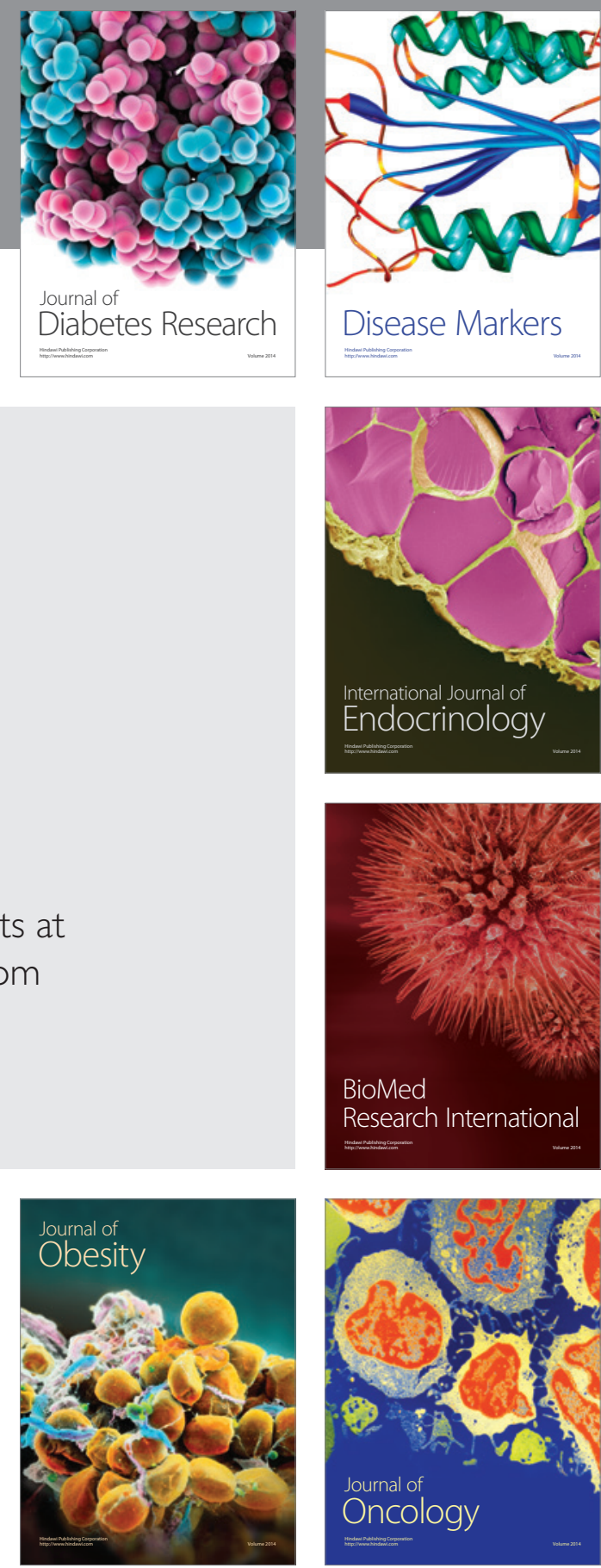

Disease Markers
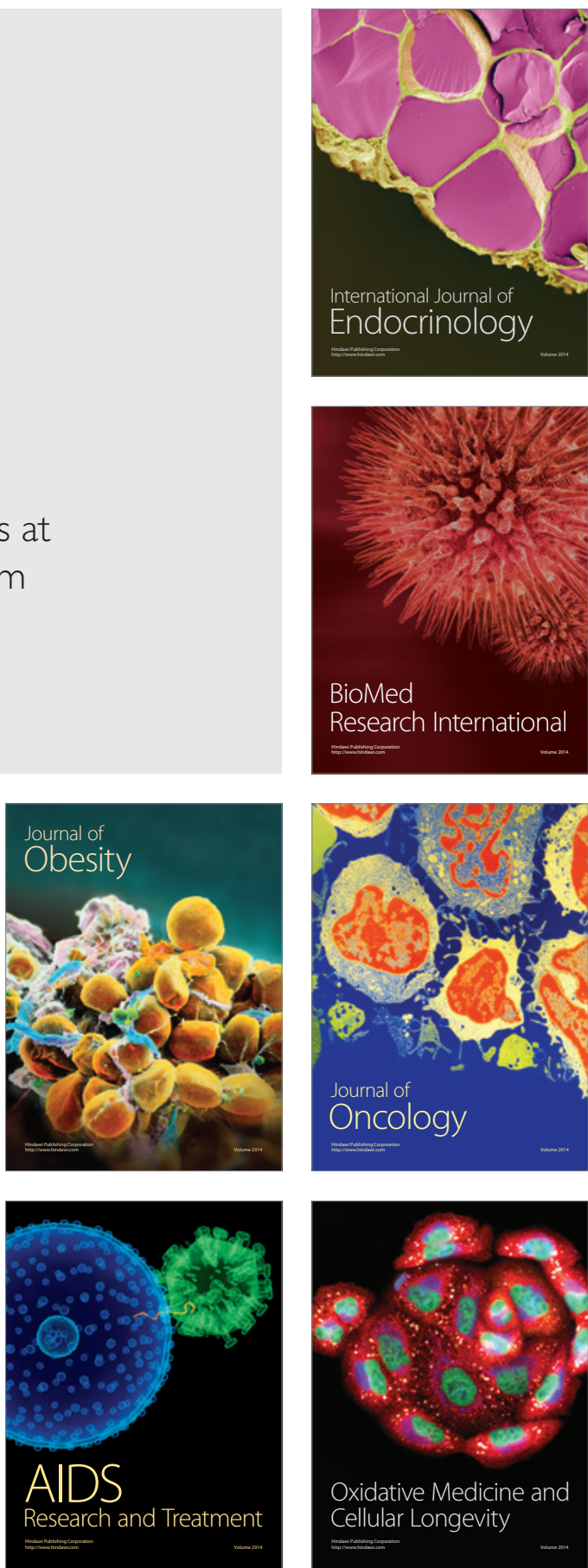